\title{
Injuries in Swedish elite football - a prospective study on injury definitions, risk for injury and injury pattern during 2001
}

\author{
Markus Waldén, Martin Hägglund and Jan Ekstrand
}

\section{Linköping University Post Print}

\section{Tweet}

N.B.: When citing this work, cite the original article.

This is the pre-reviewed version of the following article:

Markus Waldén, Martin Hägglund and Jan Ekstrand, Injuries in Swedish elite football - a prospective study on injury definitions, risk for injury and injury pattern during 2001, 2005, Scandinavian Journal of Medicine and Science in Sports, (15), 2, 118-125.

which has been published in final form at:

http://dx.doi.org/10.1111/j.1600-0838.2004.00393.x

Copyright: Wiley-Blackwell

http://eu.wiley.com/WileyCDA/Brand/id-35.html

Postprint available at: Linköping University Electronic Press http://urn.kb.se/resolve?urn=urn:nbn:se:liu:diva-14381 
INJURIES IN SWEDISH ELITE FOOTBALL. A prospective study on injury definitions, risk for injury and injury pattern during 2001

Markus Waldén MD ${ }^{1,3}$

Martin Hägglund PT ${ }^{1,2}$

Jan Ekstrand MD, $\mathrm{PhD}{ }^{1,2}$

${ }^{1}$ Department of Health and Society, Division of Social Medicine and Public Health Science, Linköping University, Linköping, Sweden

${ }^{2}$ Sports Clinic, Solstigen 3, S-589 43 Linköping, Sweden

3 Department of Orthopaedics, Hässleholm-Kristianstad Hospitals, S-281 25 Hässleholm, Sweden

Corresponding author:

Markus Waldén MD

Department of Orthopaedics, Hässleholm-Kristianstad Hospitals

S-281 25 Hässleholm, Sweden

Tel: + 4645186470, fax: + 4645186478

markus.walden@telia.com 


\section{ABSTRACT}

The purpose of this study was to study the risk for injury and injury pattern in Swedish male elite football and to compare two different injury definitions. A prospective cohort study was conducted during 2001 on all fourteen teams (310 players) in the Swedish top division. Injuries and individual exposure were recorded. Injury was defined as timelost injury (715 injuries) and for comparison as tissue injury (765 injuries). No significant difference in the risk for injury between tissue injuries and time-lost injuries was found during matches (27.2 vs. 25.9 injuries per 1000 match hours, $\mathrm{p}=0.66)$ or training sessions (5.7 vs. 5.2 injuries per 1000 training hours, $\mathrm{p}=0.65$ ). The risk for injury during training was significantly higher during the pre-season compared to the competitive season $(\mathrm{p}=0.01)$.

Thigh strain was the single most common injury (14\%). Knee sprain was the most common major injury (absence > 4 weeks). Overuse injuries and re-injuries were frequent and constituted $37 \%$ and $22 \%$ of all injuries. Re-injuries caused significantly longer absence than their corresponding initial injuries $(\mathrm{p}=0.02)$. The risk for re-injury $(p=0.02)$ and overuse injury $(p<0.01)$ was significantly higher during the pre-season compared to the competitive season.

\section{KEY WORDS}

Definition, epidemiology, incidence, soccer, sports injuries 


\section{INTRODUCTION}

Football is the most popular sport worldwide with around 200 million licensed players according to FIFA (Federation of International Football Associations). In Sweden, there are around 160000 licensed male players and elite players in the top division are with few exceptions full-time professionals.

There are several studies addressing the epidemiology and traumatology of male adult football (Ekstrand \& Gillquist, 1983a; Ekstrand, Gillquist, Möller, Öberg, Liljedahl, 1983; Ekstrand, Gillquist, Liljedahl, 1983; Lewin, 1989; Nielsen \& Yde, 1989; Ekstrand \& Tropp, 1990; Engström, Forssblad, Johansson, Törnkvist, 1990; Poulsen, Freund, Madsen, Sandvej, 1991; Árnason, Gudmundsson, Dahl, Jóhannsson, 1996; Inklaar, Bol, Schmikli, Mosterd, 1996; Lüthje et al., 1996; Hawkins \& Fuller, 1999; Dvorak \& Junge, 2000; Junge \& Dvorak, 2000; Peterson, Junge, Chomiak, Graf-Baumann, Dvorak, 2000; Hawkins, Hulse, Wilkinson, Hodson, Gibson, 2001; Morgan \& Oberlander, 2001; Woods, Hawkins, Hulse, Hodson, 2002; Hägglund, Waldén, Ekstrand, 2003). From these studies, it is evident that the majority of injuries affect the lower extremities and the ankle and knee joints are the most frequent injury locations. For adult male players the injury incidence is reported to be around 12 to 35 injuries per 1000 match hours and 1.5 to 7.6 per 1000 training hours regardless of the influence of the injury definition or level of play (Dvorak \& Junge, 2000).

Many authors have pointed out the dilemma that there is no consensus on study design, data collection, injury definition and observation period making comparison between 
studies difficult (Keller, Noyes, Buncher, 1987; Noyes, Lindenfeld, Marshall, 1988; van Mechelen, Hlobil, Kemper, 1992; Inklaar, 1994; Dvorak \& Junge, 2000; Junge \& Dvorak, 2000). Injury definitions based on time loss from exposure are most widely used in the literature, but several other football injury definitions also exist (Keller et al., 1987; Noyes et al., 1988; van Mechelen et al., 1992; Inklaar, 1994; Junge \& Dvorak, 2000; Ekstrand \& Karlsson, 2003). Recently, a concept of tissue injury was introduced (Junge \& Dvorak, 2000). To our knowledge, no prospective comparison between different injury definitions has been conducted so far.

The purposes of this study were to prospectively study the risk for injury and injury pattern and to compare the time-lost and tissue injury definitions. Our hypothesis was that there is no significant difference between tissue injuries and time-lost injuries. 


\section{MATERIALS AND METHODS}

A prospective cohort study of exposure and injuries in Swedish male elite football was carried out during the season of 2001 (January to October). The season consists of preseason (January to March) and competitive season (April to October). All competitive matches are played on natural grass. No indoor season exists. During December 2000, all 14 clubs of the Swedish top division were informed about the study and all clubs agreed to take part in the study.

During the first month of the study (January), all players of the first team squads were invited to voluntarily participate in the study. Players who were injured at the start of the study were included but their injuries at that time were not taken into account. Players contracted to the teams after January were not included. Signed informed consent from all participating players was obtained as well as information about anthropometric data, previous operations and major injuries. Totally, 310 out of 312 players (range 18-25 players/team) were included. One player did not consent to participate from the start of the study and the other player withdrew his consent after three study months. During the study 31 players (10\%) dropped out: 28 players due to team transfer; two players due to transfer to the youth team; one player had to give up football because of illness. Data from the players who dropped out during the study are included in the analyses for their entire time of participation.

All clubs had contact persons responsible for documenting individual exposure in minutes during all training sessions and matches with the club and national teams on a 
standard attendance record sheet. A training session was defined as any coach-directed scheduled physical activity carried out with the team. A match was defined as any scheduled friendly or competitive match with the club (first, second and youth teams) or national teams.

All teams had club medical staff consisting of a physician together with a physiotherapist or naprapath. At least one member of the medical team attended training sessions and matches. The club doctors were responsible for the diagnosis and treatment of the injuries. All injuries were documented immediately after the event on a standard injury card. The injury card provided information on the date of injury, scheduled activity (match or training), type, location, side, re-injury and for match injuries if there was foul play. Injury was defined: (a) according to Ekstrand (1982) as any injury occurring during scheduled training sessions or matches causing the player to miss the next training session or match (time-lost injury), and (b) according to Junge \& Dvorak (2000) as any tissue damage caused by football regardless of subsequent absence from matches or training sessions (tissue injury). Injuries occurring in leisure time or with other sports were not taken into account in the injury statistics.

The injuries were divided into traumatic and overuse injuries. Traumatic injuries were characterised by acute onset and they are shown in Table 1 . The definition of overuse injury was modified from Orava (1980) and defined as a pain syndrome of the musculoskeletal system with insidious onset and without any known trauma or disease that might have given previous symptoms. A player was considered fully rehabilitated when the medical team allowed return to full participation in training sessions or match, 
but was defined as injured if alternative training was allowed and performed. Each injury was followed until the final rehabilitation date. Two players had to end their football careers because of injury and in these cases the day of decision was calculated as the last day of injury. A re-injury was defined as the same type of injury to the same side and location within two months after the final rehabilitation day of the previous injury. Foul play was defined according to the decision of the referee (own or opponent foul) and was reported by the contact person. Injuries were classified into four categories of severity according to the length of absence from training sessions and matches including the day of injury: slight ( $<3$ days); minor (4-7 days); moderate (8-28 days); major (>28 days).

To reduce bias in data collection, all clubs were provided with a manual containing information about the study design and definitions including fictive examples and scenarios. The attendance record sheets and injury cards were sent each month by the contact person to the study group. For the purpose of the database all teams and players were coded.

The study was approved by the Ethics Committee of Linköping University, Sweden.

Statistical analysis was performed according to Armitage \& Berry (1994). Anthropometric data for age, height and weight showed a normal distribution and team differences were analysed using ANOVA (Analysis of Variance). The injury incidences and training/match-ratios showed a non-normal distribution and differences between time-lost and tissue injuries were analysed using the Mann-Whitney U test. Differences 
in injury incidence between training and match and between pre-season and competitive season were analysed using the Wilcoxon signed rank test as well as differences in training/match-ratio between pre-season and competitive season.

For the purpose of comparisons with previous studies from Sweden, most analyses were performed for the time-lost injury definition. The time-lost injury incidences for reinjury, overuse injury and major injury during pre-season and competitive season showed a non-normal distribution and differences between pre-season and competitive season were analysed with the Wilcoxon signed rank test. Foul play comparisons were analysed with the chi-square test. The severity of initial injuries and re-injuries was not normally distributed and differences between them were analysed with the Wilcoxon signed rank test. The significance level was set at $5 \%(\mathrm{p}<0.05)$. Results are expressed as mean value \pm standard deviation $(\mathrm{SD})$. 


\section{RESULTS}

There were on average 22 players per team (range 17-25) with mean age 25 years (range 17-38), mean height $182 \mathrm{~cm}$ (range 168-198) and mean weight $79 \mathrm{~kg}$ (range 6298). There were no differences between the teams regarding anthropometric data.

\section{Exposure}

The overall exposure to football was 93353 hours (81 801 training hours and 11552 match hours). The highest number of mean scheduled activities was found in March (33 activities) followed by May (31 activities). The attendance rate at training was $82 \%$ over the season. The mean training/match-ratio was $5.9 \pm 0.7$ and significantly higher during the pre-season compared to the competitive season $(8.7 \pm 1.9$ vs. $5.1 \pm 0.8, \mathrm{p}=0.001)$.

\section{Risk for injury}

In total, 240 players (77\%) incurred 765 tissue injuries and 238 players (77\%) incurred 715 time-lost injuries. The number of injuries and the distribution between match and training injuries as well as between traumatic and overuse injuries are shown in Table 3. There were no differences in injury incidences between tissue injuries and time-lost injuries during matches $(27.2 \pm 17.0$ vs. $25.9 \pm 16.0$ injuries per 1000 match hours, $\mathrm{p}=0.66)$, training sessions $(5.7 \pm 3.7$ vs. $5.2 \pm 3.2$ injuries per 1000 training hours, $\mathrm{p}=0.65)$ or total exposure $(8.3 \pm 5.0$ vs. $7.8 \pm 4.5$ injuries per 1000 exposure hours, $\mathrm{p}=0.44)$. The risk for injury during matches was significantly higher than during training $(\mathrm{p}=0.001)$ and the time-lost injury incidence during training was significantly higher during the pre-season compared to the competitive season $(8.0 \pm 4.9$ vs. $3.7 \pm 2.3$ 
time-lost injuries per 1000 training hours, $\mathrm{p}=0.001$ ). No difference was seen in the match injury incidences between the pre-season and the competitive season.

\section{Injury locations and traumatic injury types}

The time-lost injury types and locations are shown in Table 4 and 5, respectively. Eighty-seven percent of the time-lost injuries affected the lower extremities with the thigh as the most common injury location $(23 \%)$. The single most common injury subtype was thigh strain representing 14\% (98/715) of all injuries and 59\% (98/165) of all thigh injuries. Eighty percent of the strains were located to the groin (18\%) or thigh regions $(62 \%)$. Ninety-three percent of the sprains were located to the ankle $(54 \%)$ or knee joints (39\%). Isolated injury to the medial collateral ligament was the most common knee sprain constituting 54\% (21/39) of all knee sprains. Among the joint

injuries, there were thirteen isolated meniscus lesions of the knee. Five cerebral concussions were also reported.

The tissue injuries with no exposure loss consisted mainly of contusions (19/50) and sprains (17/50) and the most common locations were the ankle (12/50) and the thigh (9/50) whereas only one injury was located to the groin. No fracture was recorded among these tissue injuries.

\section{Injury severity}

The severity for time-lost injuries is shown in Table 6. Mean absence because of injury was fourteen (range 1-361) days resulting in on average ten missed training sessions and 1.5 matches. The knee was the most frequent location of major injuries and seventy- 
nine percent (19/24) of the major knee injuries were either sprains or joint injuries. Twenty-five percent of the major injuries occurred in May. Half of the major sprains (7/14) occurred in May and consisted of one ankle sprain and six knee sprains (one anterior cruciate ligament injury, one posterior cruciate ligament injury and four medial collateral ligament injuries).

\section{Overuse injuries and re-injuries}

Overuse injuries and re-injuries constituted $37 \%$ and $22 \%$ of all time-lost injuries, respectively. Three-quarters of the overuse injuries (75\%) and re-injuries (74\%) occurred during training. Thirty-eight percent of the overuse injuries were re-injuries and conversely $63 \%$ of the re-injuries were overuse injuries. The groin $(27 \%)$ and lower leg regions (23\%) accounted for half of the overuse injuries. Ten percent of the sprains (10\% of knee sprains and $11 \%$ of ankle sprains) and $17 \%$ of the strains (22\% of thigh strains) were re-injuries. Similarly, $24 \%$ of the groin injuries and $21 \%$ of the major injuries were re-injuries.

In total, $40 \%$ of all injuries and half of the overuse injuries were recorded during the pre-season as seen in Figure 1 as well as $51 \%$ of the re-injuries. The risk for overuse injury was significantly higher during the pre-season compared to the competitive season $(4.2 \pm 2.9$ vs. $2.1 \pm 2.2, p<0.01)$ as well as the risk for re-injury $(2.7 \pm 3.0$ vs. 1.3 $\pm 1.2, \mathrm{p}=0.02)$.

Seventy-nine players $(25 \%)$ had at least one re-injury during the season. Forty-six of the reported re-injuries had their corresponding initial injury prior to the start of the study 
and the lengths of absence for these initial injuries are unknown. The 112 re-injuries with prospectively recorded absence data for the initial injuries had significantly longer mean absence than the initial injuries $(10.9 \pm 15.1$ vs. $7.6 \pm 7.1$ days, $p=0.02)$. Eight of the tissue injuries with no exposure loss $(8 / 50)$ were followed by identical injuries resulting in time loss later during the season (7/8 within two months).

\section{Foul play}

Twenty percent of the time-lost injuries during matches were due to foul play (60/294). These injuries consisted of $60 \%$ contusions and $25 \%$ sprain or joint injuries. Thirty-six percent of the knee sprains $(8 / 22)$ and twenty-nine percent of the ankle sprains $(6 / 21)$ occurring during matches were due to opponent fouls. Three of the foul play injuries were due to own fouls. There was no significant difference in injury severity between own and opponent fouls or between fouls and non-fouls. 


\section{DISCUSSION}

The principal findings of this study were that the majority of all tissue injuries also resulted in time loss from football and that the frequencies of re-injuries and overuse injuries were high.

\section{Injury definitions}

There is probably no ideal injury definition and every known definition has advantages as well as disadvantages depending on the purpose of each study. In the present study, two different injury definitions were compared (time-lost injury and tissue injury) and we were not able to find any significant differences in injury incidence between them.

The time-lost definition is widely used in football epidemiology research and has also been recommended previously by Keller et al. (1987) and Noyes et al. (1988) as the preferable injury definition. However, as pointed out in some studies the time-lost injury definition has certain limitations (Keller et al., 1987; Noyes et al., 1988; Junge \& Dvorak, 2000). First, the time-lost injury definition depends on the frequency of training sessions and matches. At lower level football without daily exposure, an injury might heal between two distant sessions and "falsely" not be included in the injury statistics. On the other hand, the elite players in our study were professionals and had on average 28 scheduled sessions per month with few days-off resulting in a high probability of being absent from exposure because of injury. 
Junge \& Dvorak (2000) suggested that one inaccuracy with the time-lost definition might be that an injured player could participate in training sessions but with handicapped performance or a modified exercise programme. However, the aspect of when a player is considered fit to return to football after an injury should be clarified in the study design (Ekstrand \& Karlsson, 2003). In the present study, a player was considered fully rehabilitated when the medical team allowed full participation in team training or match.

Other factors, such as the availability of medical treatment or the importance of the match, has according to Junge \& Dvorak (2000) also been suggested to influence participation. Lower level teams usually have less medical support compared to higher levels which may affect the injury reporting and thus interfere with comparisons between different playing levels. The importance of the match or the individual player might introduce a conflict between proper injury treatment and the needs for the coach and this issue might be an even greater problem in lower levels with less medical support. There is also a risk that a player will not report any complaints if he really wants to play. Finally, the time-lost injury definition is also sport-specific (for example, a broken finger would not necessarily prevent someone from playing football, but it would probably prevent someone from playing handball).

The tissue injury definition is equally dependent as the time-lost injury definition on a medical team for making correct diagnoses. However, defining injury according to tissue damage might be even more dependant on having clinical examinations performed in close proximity to the event. Minor tissue damage heals quickly and with 
a delayed clinical examination these injuries could easily be overlooked. However, in the study by Junge \& Dvorak (2000) a physician visited the clubs once a week to document the injuries and no specific diagnostic criteria for tissue injury were reported.

Another weakness is that physical contacts and collisions are a natural part of football itself and there might be difficulties in demarcating normal contacts from tissue injuries. Therefore, the number of tissue injuries in the current study might represent a minimum amount which could explain why no differences were found. Finally, subjective complaints without simultaneous objective signs of injury might also confuse injury recording according to the tissue injury concept. This could be the first signs of an overuse injury, but the inability of the examiner to localise the tissue damage might also be an explanation.

Injury reports from daily sports papers enabled us to match our material with the material of the media. This might have further increased the accuracy of this study, since there was no reported injury to the media that was not reported to us. However, the heterogeneity of the club medical teams with many people involved in injury management is a weakness of our study. To minimise bias, all club medical team members were provided with a manual containing definitions and examples facilitating optimal recording. No specific test to evaluate the inter-rater reliability was, however, conducted. 


\section{Risk for injury}

Regardless of the injury definition, the injury incidence in football should preferably be calculated as the number of new injuries per 1000 hours of participation (van Mechelen et al., 1992). In the present study, the injury incidence is based on real exposure time in the clubs as well as in the national teams. Previous studies have often made an approximate extrapolation of exposure during the study period and no consideration has been taken to the additional exposure with national teams in studies at elite level. The exposure of substitutes at a match has often also been neglected as well as the exposure loss for players being ill or being sent-off etc.

The risk for time-lost injury during training in the present study (5.2 injuries per 1000 training hours) is in agreement with other studies using a similar definition. Regardless of the level of play, the risk for injury has been reported to be fairly constant between 2.3 and 7.6 injuries per 1000 training hours (Ekstrand et al., 1983; Nielsen \& Yde, 1989: Ekstrand \& Tropp, 1990; Engström et al., 1990; Poulsen et al., 1991; Árnason et al., 1996; Hawkins \& Fuller, 1999). The risk for injury during training was found to be higher during the pre-season. That more injuries occur during the pre-season has recently also been reported in English professional football (Woods et al., 2002). However, in that study the actual risk for injury is unknown because of absent exposure data. A possible explanation for the lower risk for injury during the competitive season in the current study might be that training is less intense with more focus on recovery after matches and/or tactical practise before next match. 
The time-lost injury incidence of 25.9 per 1000 match hours in the present study is identical to the injury incidence of four English professional teams although the injury definition differs slightly (Hawkins \& Fuller, 1999). The highest reported match injury incidence so far using a similar time-lost injury definition, 34.8 per 1000 match hours, was reported from Icelandic elite football (Árnason et al., 1996). The authors explain the high injury incidence in that study by a short competitive season and tight match schedule as well as bad weather conditions. In Sweden, previous studies at elite level conducted more than a decade ago reported injury incidences of 21.8 and 13 injuries per 1000 match hours, respectively (Ekstrand \& Tropp, 1990; Engström et al., 1990). In these studies, the players were semi-professionals and no national team data were collected which could possibly explain a lower injury incidence. However, another recent study has shown that in spite of a marked increase in exposure, there was no significant difference in the risk for injury among male elite football players in Sweden between 1982 and 2001 (Hägglund et al., 2003).

\section{Re-injuries}

The frequency of re-injuries in the present study was high (22\%). Other studies have reported re-injuries to constitute between $7-42 \%$ of all injuries (Nielsen \& Yde, 1989; Árnason et al., 1996; Hawkins \& Fuller, 1999; Hawkins et al., 2001). However, only two of these studies have clearly defined what constitutes a re-injury (Nielsen \& Yde, 1989; Hawkins et al., 2001), and fair comparison between the studies is thus difficult. Some sort of time limit in the definition of re-injury seems crucial, since it has been shown that retrospectively collected injury data introduces significant recall bias (Junge \& Dvorak, 2000). The time limit of two months in our re-injury definition is based on 
the results of the study on male amateurs by Ekstrand \& Gillquist (1983b) who could show that $35 \%$ of moderate and major injuries were preceded within two months by a minor injury. As many as forty-one percent of these injuries were of the same type and occurred to the same side and location (re-injuries).

In the present study, almost two-thirds of the re-injuries were overuse injuries. A possible explanation for the high frequency of recurrent overuse injuries might be that it is more difficult to predict an adequate rehabilitation time for overuse injuries compared to traumatic injuries. However, inadequate rehabilitation and premature return to football after strains and sprains resulting in re-injury has also been reported (Ekstrand \& Gillquist, 1983b; Nielsen \& Yde, 1989; Árnason et al., 1996). Around half of the strains (44-61\%) are reported to be re-injuries (Nielsen \& Yde, 1989; Árnason et al., 1996; Hawkins \& Fuller, 1999; Hawkins et al., 2001), whereas for sprains the re-injury frequency (18-58\%) varies more (Árnason et al., 1996; Hawkins \& Fuller, 1999; Hawkins et al., 2001). In the present study, the proportions of recurrent strains (17\%) and sprains (10\%) were considerably lower, but these frequency rates might be influenced by a narrower re-injury definition in our study. In concordance with Hawkins et al. (2001), we also found that re-injury had significantly longer absence than did the initial injury.

\section{Overuse injuries}

In the present study, more than one-third of the time-lost injuries were due to overuse. Overuse injuries are reported to constitute between 2-37\% of all injuries (Ekstrand \& Gillquist, 1983a; Nielsen \& Yde, 1989; Engström et al., 1990; Poulsen et al., 1991; 
Árnason et al., 1996; Lüthje et al., 1996; Hawkins \& Fuller, 1999; Peterson et al., 2000; Hawkins et al., 2001). Some of the studies with the highest reported frequencies have included strains which have been regarded as acute overuse injuries (Nielsen \& Yde, 1989; Poulsen et al., 1991; Peterson et al., 2000). On the other hand, studies on English professional football have found low frequencies of overuse injuries (Hawkins \& Fuller, 1999; Hawkins et al., 2001), but in these studies periostitis, tendinitis and bursitis etc were classified as separate injury types. The majority of the overuse injuries in the present study occurred during the pre-season which has also been shown in other studies (Engström et al., 1990; Hawkins et al., 2001; Woods et al., 2002).

\section{Injury locations and traumatic injury types}

Traditionally, the knee and ankle joints are the dominating injury locations (Ekstrand \& Gillquist, 1983a; Ekstrand et al., 1983a; Nielsen \& Yde, 1989; Engström et al., 1990; Poulsen et al., 1991; Árnason et al., 1996; Peterson et al., 2000; Morgan \& Oberlander, 2001). However, in the present study, we found that injuries to the thigh were most frequent which has also been shown in Finnish elite and English professional football (Lüthje et al., 1996; Hawkins \& Fuller, 1999; Hawkins et al., 2001). Most thigh injuries are strains and it has been shown that the strain mainly affects the posterior thigh (Hawkins \& Fuller, 1999; Hawkins et al., 2001). Thigh strain was also the single most common injury subtype in the present study. However, no analysis of the relation between anterior or posterior thigh strains was possible in our study because of the design of the injury card. Strain regardless of location constituted every fifth injury in our study which is in agreement (12-30\%) with most previous similar studies (Ekstrand \& Gillquist, 1983a; Nielsen \& Yde, 1989; Engström et al., 1990; Poulsen et al., 1991; 
Árnason et al., 1996; Morgan \& Oberlander, 2001), but in English professional football strains have constituted around $40 \%$ of all injuries (Hawkins \& Fuller, 1999; Hawkins et al., 2001).

The proportions of contusions, fractures and dislocations in this study are within the range of previous findings (Ekstrand \& Gillquist, 1983a; Nielsen \& Yde, 1989; Engström et al., 1990; Poulsen et al., 1991; Árnason et al., 1996; Hawkins \& Fuller, 1999; Hawkins et al., 2001), but we found a lower relative proportion of sprains (14\%) than in previous studies with similar or identical injury definitions. In these studies, sprains have constituted between 19-49\% of all injuries (Ekstrand \& Gillquist, 1983a; Nielsen \& Yde, 1989; Engström et al., 1990; Poulsen et al., 1991; Árnason et al., 1996; Hawkins \& Fuller, 1999; Hawkins et al., 2001). If this reflects a lower risk for sprain injury is unknown since no study has reported the sprain incidence and it is not clear if the classification of sprain is similar between the studies.

\section{Injury severity}

The injury severity in the present study was in agreement with previous findings among Swedish amateurs and English professional football players (Ekstrand \& Gillquist, 1983a; Hawkins \& Fuller, 1999). One-quarter of the major injuries occurred in May and many of these were knee sprains. May had a tight training and match schedule which could affect the injury pattern, but this month is generally also warm and dry in Sweden. Hot and dry weather has in American Football been found to have a higher risk for ankle and knee sprains (Orchard, 2002; Orchard \& Powell, 2003). In the present study, we did not collect data concerning weather and ground conditions, but it might be 
possible that dry weather could increase the friction between the shoes and grass and thereby also the risk for sprains in football. 


\section{PERSPECTIVE}

Several authors have discussed the difficulties in comparing studies because of lack of methodological consensus (Keller et al., 1987; Noyes et al., 1988; van Mechelen et al., 1992; Inklaar, 1994; Dvorak \& Junge, 2000; Junge \& Dvorak, 2000; Ekstrand \& Karlsson, 2003). Consequently, the methodological differences between studies might be greater than any statistically significant differences in their results. Meaningful comparison of exposure and injury epidemiology can only be made between studies with essentially the same study design, definitions and methods. Therefore, some sort of consensus or golden standard method is promptly needed in future studies.

We propose that a full football season covering both the pre-season and the competitive season is studied and that the injury definition is based on time loss. Individual exposure recording without approximations is crucial to be able to study the actual risk for injury which should be calculated as the number of injuries per 1000 exposure hours. The injury types (traumatic, overuse and recurrent injuries) must be carefully defined, but also what constitutes a training session, match and rehabilitation. Finally, we suggest that the injury severity is based on the length of absence and neither on injury type nor treatment. 


\section{ACKNOWLEDGEMENTS}

The authors gratefully acknowledge the clubs involved in the study including the voluntarily participating players, the managerial and coaching staff, the team medical staff and the contact persons. The participating clubs during 2001 were (listed in alphabetical order): AIK, Djurgårdens IF, BK Häcken, GIF Sundsvall, Halmstads BK, Hammarby IF, Helsingborgs IF, IF Elfsborg, IFK Göteborg, IFK Norrköping, Malmö FF, Trelleborgs FF, Örebro SK and Örgryte IS.

The help of biostatistician Nadine Karlsson with statistical advice and Peter Cox (MD) and Gary Lewin (PT) with language advice is also greatly appreciated.

The authors would also like to express their gratitude to the European (UEFA) and Swedish (SvFF) Football Associations and the Swedish Sports Confederation (Sports Research Council) for financial support of the study. 


\section{REFERENCES}

Armitage P, Berry G. Statistical methods in medical research. 3rd ed. Oxford: Blackwell, 1994

Árnason Á, Gudmundsson Á, Dahl HA, Jóhannsson E. Soccer injuries in Iceland. Scand J Med Sci Sports 1996: 6: 40-45

Dvorak J, Junge A. Football injuries and physical symptoms. A review of the literature. Am J Sports Med 2000: 28: S3-S9

Ekstrand J. Soccer injuries and their prevention. Linköping University Medical Dissertations, No 130, Sweden, 1982

Ekstrand J, Gillquist J. Soccer injuries and their mechanisms: a prospective study. Med Sci Sports Exerc 1983a: 15: 267-270

Ekstrand J, Gillquist J, Möller M, Öberg B, Liljedahl S-O. Incidence of soccer injuries and their relation to training and team success. Am J Sports Med 1983a: 11: 63-67

Ekstrand J, Gillquist J. The avoidability of soccer injuries. Int J Sports Med 1983b: 4: $124-128$ 
Ekstrand J, Gillquist J, Liljedahl S-O. Prevention of soccer injuries. Supervision by doctor and physiotherapist. Am J Sports Med 1983b: 11: 116-120

Ekstrand J, Tropp H. The incidence of ankle sprains in soccer. Foot \& Ankle 1990: 11: $41-44$

Ekstrand J, Karlsson J. Editorial: The risk for injury in football. There is a need for a consensus about definition of the injury and the design of studies. Scand J Med Sci Sports 2003: 13: 147-149

Engström B, Forssblad M, Johansson C, Törnkvist H. Does a major knee injury definitely sideline an elite soccer player? Am J Sports Med 1990: 18: 101-105

Hawkins RD, Fuller CW. A prospective epidemiological study of injuries in four English professional football clubs. Br J Sports Med 1999: 33: 196-203

Hawkins RD, Hulse MA, Wilkinson C, Hodson A, Gibson M. The association football medical research programme: an audit of injuries in professional football. Br J Sports Med 2001: 35: 43-47

Hägglund M, Waldén M, Ekstrand J. Exposure and injury risk in Swedish elite football: a comparison between seasons 1982 and 2001. Scand J Med Sci Sports 2003: 13: 364370 
Inklaar H. Soccer injuries I: injuries and severity. Sports Med 1994: 18: 55-73

Inklaar H, Bol E, Schmikli SL, Mosterd WL. Injuries in male soccer players: team risk analysis. Int J Sports Med 1996: 17: 229-234

Junge A, Dvorak J. Influence of definition and data collection on the incidence of injuries in football. Am J Sports Med 2000: 28: S40-S46

Keller CS, Noyes FR, Buncher CR. The medical aspects of soccer injury epidemiology. Am J Sports Med 1987: 15: 230-237

Lewin G. The incidence of injuries in an English professional soccer club during one competitive season. Physiotherapy 1989: 75: 601-605

Lüthje P, Nurmi I, Kataja M, Belt E, Helenius P, Kaukonen JP, Kiviluoto H, Kokko E, Lehtipuu TP, Lehtonen A, Liukkonen T, Myllyniemi J, Rasilainen P, Tolvanen E, Virtanen H, Walldén M. Epidemiology and traumatology of injuries in elite soccer: a prospective study in Finland. Scand J Med Sci Sports 1996: 6: 180-185

Morgan BE, Oberlander MA. An examination of injuries in major league soccer. The inaugural season. Am J Sports Med 2001: 29: 426-430

Nielsen AB, Yde J. Epidemiology and traumatology of injuries in soccer. Am J Sports Med 1989: 17: 803-807 
Noyes FR, Lindenfeld TN, Marshall MT. What determines an athletic injury (definition)? Who determines an injury (occurrence)? Am J Sports Med 1988: 16: S6568

Orava S. Exertion injuries due to sports and physical exercise. A clinical and statistical study of nontraumatic overuse injuries of the musculoskeletal system of athletes and keep-fit athletes. PhD thesis, University of Oulu, Finland, 1980

Orchard J. Is there a relationship between ground and climatic conditions and injuries in football. Sports Med 2002: 32: 419-432

Orchard JW, Powell JW. Risk of knee and ankle sprains under various weather conditions in American Football. Med Sci Sports Exerc 2003: 35: 1118-1123

Peterson L, Junge A, Chomiak J, Graf-Baumann T, Dvorak J. Incidence of football injuries and complaints in different age groups and skill-level groups. Am J Sports Med 2000: 28: S51-S57

Poulsen TD, Freund KG, Madsen F, Sandvej K. Injuries in high-skilled and low-skilled soccer: a prospective study. Br J Sports Med 1991: 25: 151-153

van Mechelen W, Hlobil H, Kemper HCG. Incidence, severity, aetiology and prevention of sports injuries. A review of concepts. Sports Med 1992: 14: 82-99 
Woods C, Hawkins R, Hulse M, Hodson A. The Football Association Medical Research Programme: an audit of injuries in professional football - analysis of preseason injuries. Br J Sports Med 2002: 36: 436-441 


\section{TABLE LEGENDS}

Table 1 Classification of traumatic injury types

Table 2 Number of injuries

Table 3 Injury types and severity (time-lost injuries)

Table 4 Injury locations and severity (time-lost injuries)

Table 5 Injury severity and absence (time-lost injuries) 


\section{TABLES}

Table 1. Classification of traumatic injury types

Sprain Acute distraction injury of ligaments or joint capsules

Joint injury Acute isolated chondral and meniscus lesions

Strain $\quad$ Acute distraction injury of muscles and tendons

Contusion Tissue bruise without concomitant injuries classified elsewhere

Fracture Traumatic break of bone

Dislocation Partial (subluxation) or complete (luxation) displacement of the bony parts of a joint

Other Injuries not classified elsewhere. Examples: wound, concussion etc 
Table 2. Number of injuries

\begin{tabular}{|llll|}
\hline & Match & Training & Total \\
& N & N & N \\
\hline Tissue injuries & 309 & 456 & 765 \\
- traumatic & 242 & 255 & 497 \\
- overuse & 67 & 201 & 268 \\
\hline Time-lost injuries & 294 & 421 & 715 \\
- traumatic & 228 & 226 & 454 \\
- overuse & 66 & 195 & 261 \\
\hline
\end{tabular}


Table 3. Injury types and severity (time-lost injuries)

\begin{tabular}{|llllll|}
\hline & Injuries & Slight & Minor & Moderate & Major \\
& $\mathbf{N}(\%)$ & $\mathbf{N}(\%)$ & $\mathbf{N}(\%)$ & $\mathbf{N}(\%)$ & $\mathbf{N}(\%)$ \\
\hline Sprain & $99(14)$ & $34(14.5)$ & $27(12)$ & $33(13)$ & $20(21)$ \\
\hline Joint injury & $15(2)$ & $1(0.5)$ & $3(1.5)$ & $5(2)$ & $6(9)$ \\
\hline Strain & $158(22)$ & $15(6.5)$ & $53(27)$ & $75(34)$ & $15(22)$ \\
\hline Contusion & $122(17)$ & $62(27)$ & $35(18)$ & $24(11)$ & $1(2)$ \\
\hline Fracture & $20(3)$ & $3(1)$ & $2(1)$ & $7(3.5)$ & $8(12)$ \\
\hline Dislocation & $6(1)$ & $1(0.5)$ & $2(1)$ & $3(1)$ & $0(0)$ \\
\hline Other & $33(4.5)$ & $14(6)$ & $9(4.5)$ & $5(2)$ & \\
\hline Overuse & $262(36.5)$ & $103(44)$ & $68(35)$ & $73(33.5)$ & $18(27)$ \\
\hline Total & $715(100)$ & $232(100)$ & $196(100)$ & $220(100)$ & $67(100)$ \\
\hline
\end{tabular}

The approximations of the percentages have been made to equal $100 \%$ 
Table 4. Injury locations and severity (time-lost injuries)

\begin{tabular}{|c|c|c|c|c|c|}
\hline & $\begin{array}{l}\text { Injuries } \\
\mathbf{N}(\%)\end{array}$ & $\begin{array}{l}\text { Slight } \\
\text { N (\%) }\end{array}$ & $\begin{array}{l}\text { Minor } \\
\text { N }(\%)\end{array}$ & $\begin{array}{l}\text { Moderate } \\
\text { N (\%) }\end{array}$ & $\begin{array}{l}\text { Major } \\
\text { N (\%) }\end{array}$ \\
\hline Head/face/neck & $16(2)$ & $8(3.5)$ & $6(3)$ & $2(1)$ & $0(0)$ \\
\hline Back & $43(6)$ & $20(9)$ & $12(6)$ & $7(3)$ & $4(6)$ \\
\hline Hip/groin & $114(16)$ & 40 (17) & $25(13)$ & $35(16)$ & $14(21)$ \\
\hline Thigh & $165(23)$ & $43(18.5)$ & $52(27)$ & $61(27)$ & $9(13)$ \\
\hline Knee & $111(16)$ & $29(12)$ & $21(11)$ & 37 (17) & $24(36)$ \\
\hline Lower leg & $109(15)$ & $38(16)$ & 35 (18) & $29(13.5)$ & $7(10)$ \\
\hline Ankle & $73(10)$ & $23(10)$ & $25(12)$ & $22(10)$ & $3(5)$ \\
\hline Foot & $53(8)$ & $25(11)$ & $13(6.5)$ & $13(6)$ & $2(3)$ \\
\hline Other & $31(4)$ & $6(3)$ & $7(3.5)$ & $14(6.5)$ & $4(6)$ \\
\hline Total & 715 (100) & $232(100)$ & $196(100)$ & $220(100)$ & $67(100)$ \\
\hline
\end{tabular}

The approximations of the percentages have been made to equal $100 \%$ 
Table 5. Injury severity and absence (time-lost injuries)

\begin{tabular}{|lllll|}
\hline & Injuries & Absence (days) & Absence (trainings) & Absence (matches) \\
& $\mathbf{N}(\%)$ & Mean $(\mathbf{\% D})$ & Mean (SD) & Mean (SD) \\
\hline Slight & $232(32.5)$ & $2.2(0.6)$ & $1.6(1.0)$ & $0.1(0.3)$ \\
\hline Minor & $196(27.5)$ & $5.1(1.1)$ & $3.7(1.3)$ & $0.4(0.6)$ \\
\hline Moderate & $220(30.5)$ & $12.8(5.1)$ & $9.8(4.7)$ & $1.5(1.2)$ \\
\hline Major & $67(9.5)$ & $82.6(79.4)$ & $55.6(51.7)$ & $9.4(9.2)$ \\
\hline Total & $715(100)$ & $13.8(33.2)$ & $9.8(22.0)$ & $1.5(3.9)$ \\
\hline
\end{tabular}


FIGURE LEGEND

Figure 1 Seasonal distribution of traumatic and overuse injuries (time-lost injuries) 
Figure 1. Seasonal distribution of traumatic and overuse injuries (time-lost injuries)

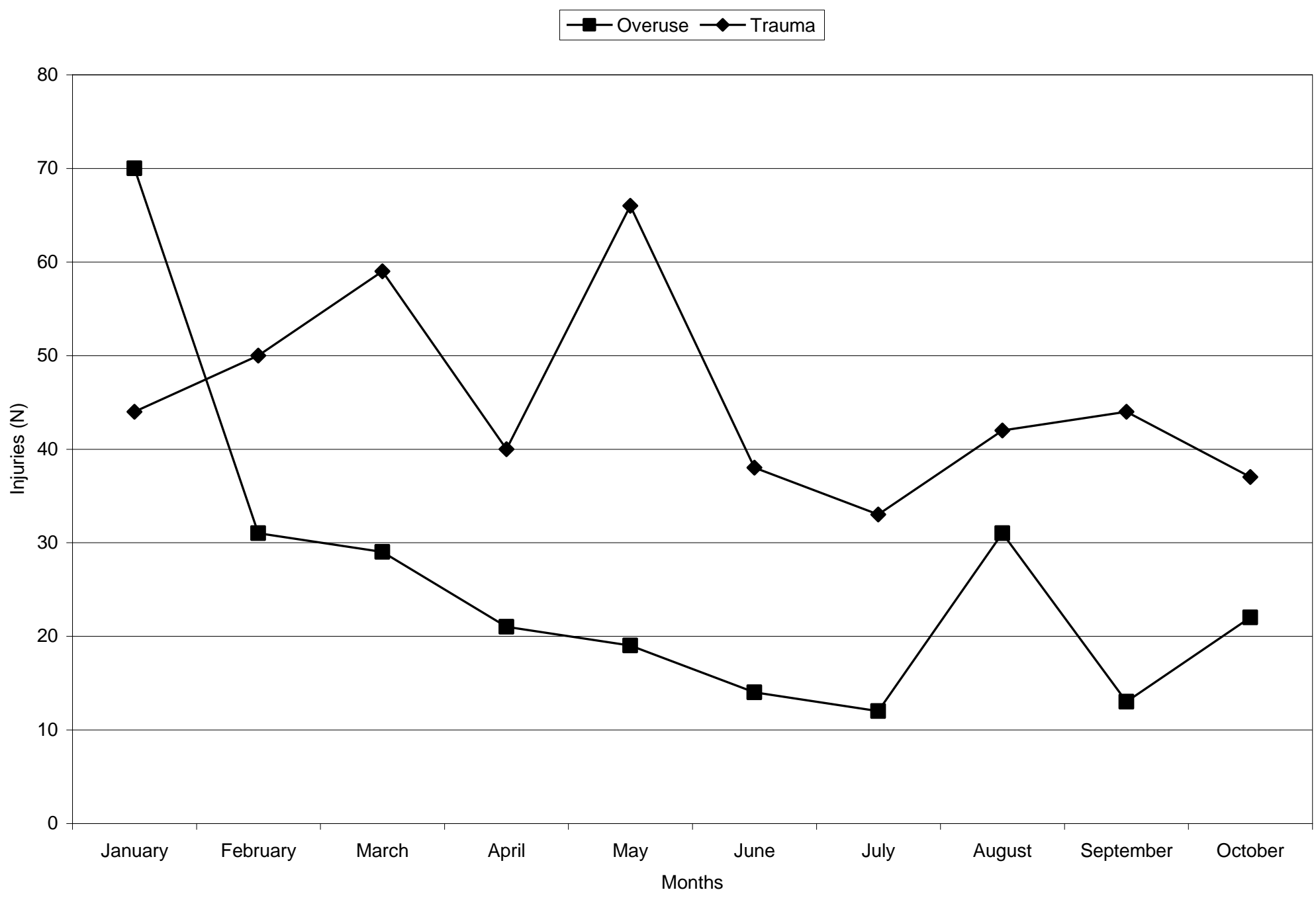

Pre-season $=$ January to March

Competitive season $=$ April to October 